\title{
Molecular epidemiology of drug-resistant malaria in western Kenya highlands
}

\author{
Daibin Zhong*1, Yaw Afrane ${ }^{2}$, Andrew Githeko², Liwang Cui³, \\ David M Menge ${ }^{4}$ and Guiyun Yan ${ }^{1}$
}

\begin{abstract}
Address: ${ }^{1}$ Program in Public Health, College of Health Sciences, University of California at Irvine, Irvine, CA 92697, USA, ${ }^{2}$ Center for Vector Biology and Control Research, Kenya Medical Research Institute, Kisumu, Kenya, ${ }^{3}$ Department of Entomology, the Pennsylvania State University, University Park, PA 16802, USA and ${ }^{4}$ Center for Infectious Diseases and Microbiology Translational Research, University of Minnesota, Minneapolis, MN 55455, USA

Email: Daibin Zhong* - dzhong@uci.edu; Yaw Afrane - yaw_afrane@yahoo.com; Andrew Githeko - agitheko1@kisian.mimcom.net; Liwang Cui - luc2@psu.edu; David M Menge - menge023@umn.edu; Guiyun Yan - guiyuny@uci.edu

* Corresponding author
\end{abstract}

Published: 31 July 2008

BMC Infectious Diseases 2008, 8:105 doi:10.1186/1471-2334-8-105
Received: 2 April 2008

Accepted: 31 July 2008

This article is available from: http://www.biomedcentral.com/I47I-2334/8/105

(c) 2008 Zhong et al; licensee BioMed Central Ltd.

This is an Open Access article distributed under the terms of the Creative Commons Attribution License (http://creativecommons.org/licenses/by/2.0), which permits unrestricted use, distribution, and reproduction in any medium, provided the original work is properly cited.

\begin{abstract}
Background: Since the late 1980s a series of malaria epidemics has occurred in western Kenya highlands. Among the possible factors that may contribute to the highland malaria epidemics, parasite resistance to antimalarials has not been well investigated.

Methods: Using parasites from highland and lowland areas of western Kenya, we examined key mutations associated with Plasmodium falciparum resistance to sulfadoxine - pyrimethamine and chloroquine, including dihydrofolate reductase ( $p f d h f r)$ and dihydropteroate synthetase (pfdhps), chloroquine resistance transporter gene ( $p f c r t)$, and multi-drug resistance gene I ( $p f m d r l)$.

Results: We found that $>70 \%$ of samples harbored $76 \mathrm{~T}$ pfort mutations and over $80 \%$ of samples harbored quintuple mutations (5II/59R/I08N pfdhfr and 437G/540E pfdhps) in both highland and lowland samples. Further, we did not detect significant difference in the frequencies of these mutations between symptomatic and asymptomatic malaria volunteers, and between highland and lowland samples.

Conclusion: These findings suggest that drug resistance of malaria parasites in the highlands could be contributed by the mutations and their high frequencies as found in the lowland. The results are discussed in terms of the role of drug resistance as a driving force for malaria outbreaks in the highlands.
\end{abstract}

\section{Background}

Malaria is a major public health problem in sub-Saharan Africa and Plasmodium falciparum infection is a leading cause of morbidity and mortality inflicting a huge economic burden in countries where the disease is endemic [1]. It is estimated that death toll of malaria exceeds one million people each year, and the victims are primarily children under the age of five [2]. Until the early 1980s, the African highlands (generally referred to areas of $>1,500 \mathrm{~m}$ above sea level) were either free of malaria or had very low incidences of the disease; however, since the late 1980s a series of malaria epidemics has occurred [3- 
9]. Among the many factors that may contribute to the highland malaria epidemics, resistance of the parasites to multiple antimalarials has not been extensively investigated. Resistance to antimalarial drugs is one of the major obstacles for effective malaria control. The first case of chloroquine (CQ) resistance in Kenya was reported in 1977 [10]. In 1993, resistance levels had reached 70\% [11]. In 1998, the Ministry of Health of Kenya changed the first line of treatment from chloroquine to sulfadoxine - pyrimethamine (SP; Fansidar ${ }^{\circledR}$ ) [12]. In 2004, the Ministry of Health of Kenya officially changed the first-line drug to artemether/lumefantrin $\left(\right.$ Coartem $\left.^{\mathrm{TM}}\right)$ [13].

Drug resistance in malaria parasites is associated with genetic mutations in target genes and can be monitored using molecular methods. CQ resistance is determined by the major point mutation at codon 76 of the P. falciparum CQ resistance transporter ( $p f c r t$ ) gene [14], which is highly correlated with increased clinical CQ tolerance and treatment failure [14-16]. In addition, point mutations in $P$. falciparum multi-drug resistance gene 1 ( $p f m d r 1$ ) (e.g., N86Y, Y183F, S1034C, N1042D, and D1246Y) have been shown to modulate CQ resistance [17] and possibly lumefantrine resistance [18]. Resistance to antifolates is associated with point mutations in the dihydrofolate reductase ( $p f d h f r)$ and dihydropteroate synthetase ( $p f d h p s)$ genes [19]. Pyrimethamine (PY) resistance is conferred by the key mutation at codon 108 in the $p f d h f r$ gene, while additional mutations at positions 51 and 59 increase the levels of resistance [20]. The 164L mutation common in Southeast Asia has been shown to confer PY resistance. Although this mutation is not common in Africa, a recent study by McCollin et al detected the $164 \mathrm{~L}$ mutation in western Kenya [21]. Similarly, sulfadoxine (SD) resistance is conferred by a key mutation at codon 437 in the pfdhps gene and modulated by additional mutations at codons 436, 540, 581, and 613 [22]. Multiple mutations in these two genes result in antifolate treatment failure [23]. Molecular methods have been developed to detect point mutations in genes responsible for drug resistance [2426], and have been widely used to monitor drug resistance in epidemiological surveys [16]. In this study, we have analyzed the mutations of antimalarial drug resistance genes for CQ ( $p f c r t$ and $p f m d r 1$ ) and antifolates ( $p f d h p s$ and $p f d h f r$ ) in samples from patients with acute malaria infections and school children with asymptomatic infections at one lowland and two highland locations in western Kenya.

\section{Methods \\ Sample collection}

Sampling in two highland sites (Kisii, elevation 1600 m above sea level; and Kakamega, elevation 1,480-1,560 m) and one neighboring lowland site (Kombewa, elevation $\sim 1200 \mathrm{~m}$ ) from June through August 2005 were con- ducted as a part of malaria surveillance activities. Average annual malaria prevalence among primary school children during the sampling period was $10.3 \%, 42.7 \%$ and $75 \%$ in Kisii, Kakamega and Kombewa, respectively. Malaria transmission intensity, measured by entomological inoculation rate (EIR), was $0.4,16.6$ and 31.1 infectious bites per person per year in Kisii, Kakamega and Kombewa, respectively [27]. At each site, 100 samples were collected from patients admitted with acute P. falciparum infection at a local hospital and 100 samples from primary school children (age 6-14 years old) with asymptomatic $P$. falciparum infections diagnosed by microscopy. Symptomatic malaria patients were treated by clinicians in the hospital with antimalarial drug, Coartem which achieved cure rates of up to $95 \%$, even in areas of multidrug resistance. Each sample consisted of $\sim 200 \mu \mathrm{l}$ of finger-prick blood spotted on filter papers. Filter papers were dried and stored at $-20^{\circ} \mathrm{C}$ until parasite DNA extraction. The human subject protocol involved in this study has been approved by University of California, Irvine (UCI) and Kenya Medical Research Institute (KEMRI). Informed consent was provided by the parents/guardians of the children and assent from the children was obtained prior to the sample collection.

\section{Parasite DNA extraction and species identification}

DNA was extracted from the blood filters using the Saponin/Chelex method [28]. Parasite DNA was extracted from one quarter of a blood spot of about $1 \mathrm{~cm}$ in diameter and dissolved in $200 \mu \mathrm{l}$ of distilled water. Three microliters of the parasite DNA were used as the template for polymerase chain reaction (PCR). To avoid complications from mixed parasite species infections, a nested PCR method was used to verify $P$. falciparum infections and exclude the presence of other Plasmodium species in each sample [29]. Approximately 3-5\% of samples containing mixed parasite species or other parasite species were identified in all the study sites. Samples containing only P. falciparum DNA were used for genotyping analysis.

\section{Molecular detection of mutations in drug targets}

Mutations in the pfcrt (K76T) and pfmdr1 genes were detected using a PCR-restriction fragment length polymorphism (RFLP) method. The fragment encompassing pfcrt codon 76 was amplified and digested with ApoI, which cleaves the wild type into 111 and 34 bp fragments [30]. Similarly, fragments containing codons 86, 184, 1034,1042 , and 1246 of the pfmdr1 gene were separately amplified by PCR and digested with respective restrictive enzymes as described previously [30-33]. Screening for mutations associated with antifolate resistance at codons $16,50,51,59,108$, and 164 of the pfdhfr gene and codons 436, 437, 540, 581, and 613 of the pfdhps gene was performed by nested PCR and mutation-specific restriction enzyme digestions [34-36]. 


\section{Statistical analysis}

The difference in frequencies of point mutations in the four aforementioned genes between highland and lowland parasite populations was determined by using the $\chi^{2}$ tests or Fisher's exact test for datasets with sample size less than 5. Yates' correction was applied for the chi-square value, resulting in corrected $P$ values. Statistical significance was taken at the $P=0.05$ level. Association between the different mutations was tested using Fisher's exact test.

\section{Results}

A total of 600 P. falciparum samples were analyzed for pfcrt, pfmdr1, pfdhfr, and pfdhps genes. Over $90 \%$ of samples were successfully amplified at the 17 test codons, and polymorphisms were detected at 10 of 17 codons screened (Table 1). Consistent with the hyperendemic settings in the study areas, we detected infections by mixed strains at seven of the 17 studied codons, which included codon 76 of pfcrt, codons 86, 184 and 1246 of pfmdr1, codon 59 of pfdhfr, and codons 437 and 540 of $p f d h p s$ (Table 1). The frequencies of mutant codons at the four genes varied slightly between the study sites, but the differences were not significant (Fig. 1). Mixed-genotype infections at $p f d h f r$ codon 59, 437, and 540 of the antifolate target genes were low $(<10 \%)$ in all samples. Similarly, mixed-genotype infections at codon 76 of the $p f c r t$ gene were low $(<15 \%)$. In contrast, mixed-genotype infections at codons 86,184 and 1246 of the $p f m d r 1$ gene were more frequent $(18-45 \%)$ (Table 1$)$.

\section{Mutations in CQ resistance genes}

Consistent with the past extensive use of CQ in this area, the pfcrt 76T mutant allele was present in $=80 \%$ (including mixed infections with wild type and mutant alleles) of all samples from the three locations (Fig. 1A and 1B). In comparison, mutations at alleles $86 \mathrm{Y}, 184 \mathrm{~F}$ and $1246 \mathrm{Y}$ of

Table I: Frequencies of mutations in genes associated with resistance to chloroquine, sulfadoxine-pyrimethamine in $P$. falciparum parasites from symptomatic and asymptomatic volunteers in western Kenya.

\begin{tabular}{|c|c|c|c|c|c|c|c|c|}
\hline \multirow[t]{2}{*}{ Gene } & \multirow[t]{2}{*}{ Mutation } & \multirow[t]{2}{*}{ Polymorphism } & \multicolumn{2}{|c|}{ Kombewa } & \multicolumn{2}{|c|}{ Kakamega } & \multicolumn{2}{|c|}{ Kisii } \\
\hline & & & $\mathrm{S}^{*}$ & $A^{*}$ & $\mathrm{~S}$ & $A$ & $\mathrm{~S}$ & A \\
\hline \multirow[t]{3}{*}{ pfort } & $\mathrm{K} 76 \mathrm{~T}$ & Mutant & 87 & 81 & 86 & 77 & 75 & 70 \\
\hline & & Mixed & 7 & 15 & 6 & 9 & 8 & 10 \\
\hline & & Wild-type & 6 & 4 & 8 & 14 & 17 & 20 \\
\hline \multirow[t]{9}{*}{ Pfmdrl } & N86Y & Mutant & 28 & 41 & 28 & 39 & 10 & 23 \\
\hline & & Mixed & 44 & 22 & 45 & 37 & 40 & 18 \\
\hline & & Wild-type & 28 & 37 & 27 & 24 & 50 & 59 \\
\hline & YI84F & Mutant & 24 & 15 & 7 & 5 & $\mathrm{II}$ & 26 \\
\hline & & Mixed & 26 & 30 & 23 & 26 & 33 & 19 \\
\hline & & Wild-type & 50 & 55 & 70 & 69 & 56 & 55 \\
\hline & DI246Y & Mutant & 24 & 37 & 40 & 28 & 42 & 24 \\
\hline & & Mixed & 42 & 30 & 36 & 44 & 21 & 29 \\
\hline & & Wild-type & 34 & 33 & 24 & 28 & 37 & 47 \\
\hline \multirow[t]{9}{*}{$p f d h f r$} & N5II & Mutant & 98 & 96 & 98 & 98 & 96 & 95 \\
\hline & & Mixed & 0 & 0 & 0 & 0 & 0 & 0 \\
\hline & & Wild-type & 2 & 4 & 2 & 2 & 4 & 5 \\
\hline & C59R & Mutant & 81 & 75 & 88 & 79 & 90 & 86 \\
\hline & & Mixed & 4 & 10 & 2 & 7 & 2 & 0 \\
\hline & & Wild-type & 15 & 15 & 10 & 14 & 8 & 14 \\
\hline & SI08N & Mutant & 100 & 100 & 100 & 100 & 100 & 100 \\
\hline & & Mixed & 0 & 0 & 0 & 0 & 0 & 0 \\
\hline & & Wild-type & 0 & 0 & 0 & 0 & 0 & 0 \\
\hline \multirow[t]{9}{*}{ pfdhps } & S436F & Mutant & 4 & 2 & 4 & 4 & 2 & 2 \\
\hline & & Mixed & 0 & 0 & 0 & 0 & 0 & 0 \\
\hline & & Wild-type & 96 & 98 & 96 & 96 & 98 & 98 \\
\hline & A437G & Mutant & 94 & 95 & 92 & 93 & 88 & 93 \\
\hline & & Mixed & 4 & 5 & 4 & 7 & 2 & 0 \\
\hline & & Wild-type & 2 & 0 & 4 & 0 & 10 & 7 \\
\hline & K540E & Mutant & 88 & 95 & 92 & 91 & 88 & 93 \\
\hline & & Mixed & 10 & 5 & 4 & 9 & 2 & 0 \\
\hline & & Wild-type & 2 & 0 & 4 & 0 & 10 & 7 \\
\hline
\end{tabular}

* S - symptomatic; A - asymptomatic.

Note: No mutations were detected at the following codons: pfdhfr (AI6V, C50R and II64L); pfdhps (S436A, A58IG and A6I3S); and pfmdrI (SI034 and NI042D). 


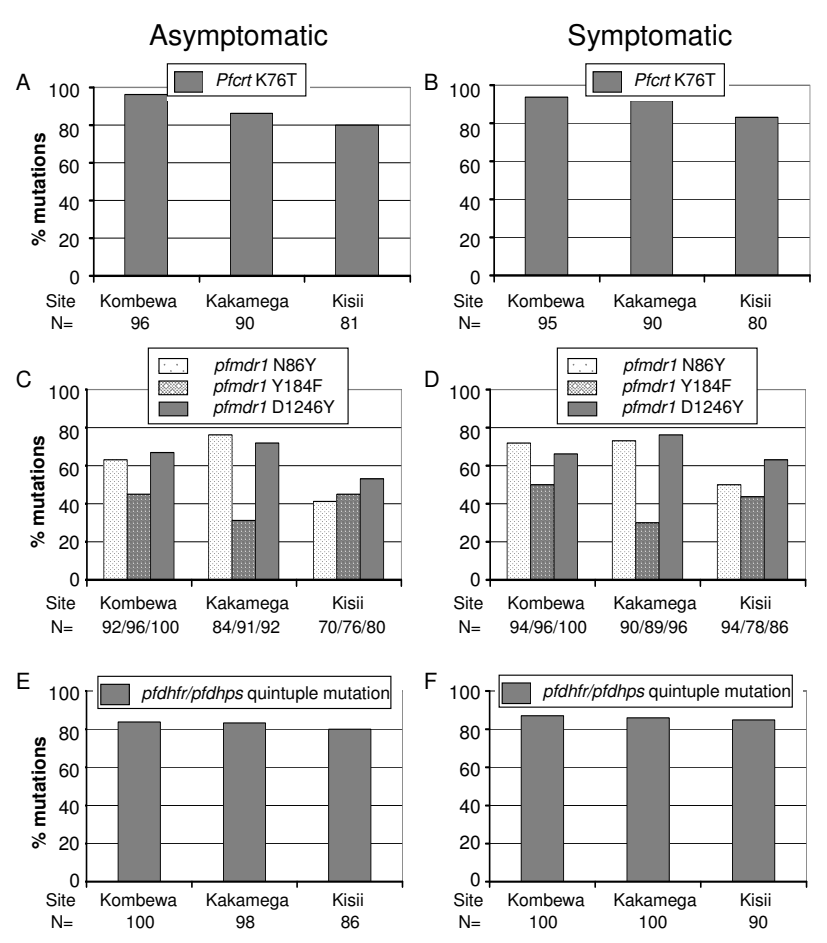

Figure I

Frequency of mutations in Plasmodium falciparum chloroquine resistance transporter gene ( $p f c r t)(A$ and $B)$, multi-drug resistance gene ( $p f m d r l)(C$ and $D)$ and quintuple mutations in dihydrofolate reductase ( $p f d h f r) / d i h y d r o p t e r o a t e ~ s y n-$ thetase (pfdhps) ( $E$ and $F$ ) genes in symptomatic and asymptomatic volunteers in highland (Kakamega and Kisii) and lowland (Kombewa) sites of western Kenya. The pfdhfrl pfdhps quintuple mutation refers to $5 \mathrm{I}$ I/59R//08N/437G/ 540E. No mutations were detected at the following codons: pfdhfr (AI6V, C50R, II64L and S436A), pfdhps (A58IG and A6I3S), and pfmdrl (SI034 and NI042D).

pfmdr1 gene were present at lower frequencies, ranging from 30 to $76 \%$ (including mixed infections) (Fig. 1C and 1D), whereas no mutation was found at codons 1034 and 1042, which was associated with CQ resistance in South America. The frequencies of mutations were generally not significantly different between the three study sites except pfcrt 76T and pfmdr1 86Y between Kombewa and Kisii $(P$ $<0.05)$, and pfmdr1 184F between Kombewa and Kakamega $(P<0.01)$ (Fig. 1E and $1 \mathrm{~F})$. Consequently, the genotype $86 \mathrm{Y} / 184 \mathrm{Y} / 1246 \mathrm{Y}$ (wildtype at codon 184) was present at a significantly higher frequency in highland than in lowland parasites $(P<0.05)$, whereas the genotype $86 \mathrm{Y} / 184 \mathrm{~F} / 1246 \mathrm{Y}$ (triple mutations) was significantly more frequent in lowland than in highland parasites (Table 2). Since certain $p f m d r 1$ alleles were found associated with CQ resistance, we compared the association between $p f m d r 1$ mutations and the major CQ-resistance determinant $p f c r t 76 \mathrm{~T}$. When all parasite samples were
Table 2: Percentage of haplotypes of $P$. falciparum parasites collected from symptomatic and asymptomatic volunteers in western Kenya.

\begin{tabular}{|c|c|c|c|c|c|c|}
\hline \multirow[t]{2}{*}{ Haplotypes } & \multicolumn{2}{|c|}{ Kombewa } & \multicolumn{2}{|c|}{ Kakamega } & \multicolumn{2}{|c|}{ Kisis } \\
\hline & $S^{*}$ & $A^{*}$ & $\mathrm{~S}$ & A & $S$ & $A$ \\
\hline \multicolumn{7}{|l|}{ Pfmdrl } \\
\hline $86 \underline{Y} / 184 Y / / 246 Y$ & 24 & 26 & 44 & 46 & 38 & 36 \\
\hline $86 \underline{\underline{Y}} / 184 \underline{F} / 1246 \underline{\underline{Y}}$ & 32 & 34 & 24 & 23 & 16 & 13 \\
\hline $86 \bar{N} / 184 \underline{F} / 1246 \bar{D}$ & 12 & 15 & 0 & 0 & 25 & 27 \\
\hline $86 \underline{Y} / 184 \underline{F} / 1246 \mathrm{D}$ & 18 & 10 & 0 & 5 & 1 & 0 \\
\hline $86 \bar{Y} / / 84 \bar{Y} / 1246 D$ & 2 & 0 & 16 & 10 & 1 & 3 \\
\hline $86 \bar{N} / 184 Y / / 246 D$ & 6 & 5 & 8 & 10 & 11 & 12 \\
\hline $86 \mathrm{~N} / 184 \underline{F} / 1246 \underline{Y}$ & 3 & 5 & 4 & 3 & 8 & 5 \\
\hline $86 \mathrm{~N} / 184 \bar{Y} / 1246 \bar{Y}$ & 3 & 5 & 4 & 3 & 0 & 4 \\
\hline \multicolumn{7}{|l|}{ Pfdhfr/pfdhps } \\
\hline \multicolumn{7}{|l|}{ Quintuple } \\
\hline $5 \mathrm{I} / 1 / 59 \underline{\mathrm{R}} / 108 \underline{\mathrm{N}} / 437 \underline{\mathrm{G}} / 540 \underline{\mathrm{E}}$ & 87 & 84 & 86 & 83 & 85 & 80 \\
\hline \multicolumn{7}{|l|}{ Quadruple } \\
\hline $51 \mathrm{I} / 59 \mathrm{C} / 108 \underline{\mathrm{N}} / 437 \underline{\mathrm{G}} / 540 \underline{\mathrm{E}}$ & 7 & 5 & 3 & 8 & 4 & 4 \\
\hline $5 \mathrm{IN} / 59 \mathrm{R} / 108 \mathrm{~N} / 437 \mathrm{G} / 540 \underline{\mathrm{E}}$ & 0 & 0 & 4 & 3 & 2 & 6 \\
\hline $51 \mathrm{I} / 59 \mathrm{R} / 108 \mathrm{~N} / 437 \mathrm{G} / 540 \mathrm{~K}$ & 1 & 5 & I & 2 & I & 2 \\
\hline $51 \underline{1} / 59 \underline{R} / 108 \underline{\underline{N}} / 437 \bar{A} / 540 \underline{E}$ & 1 & I & 0 & 0 & 3 & 4 \\
\hline \multicolumn{7}{|l|}{ Triple } \\
\hline $5 \mathrm{I} \underline{1} / 59 \underline{\mathrm{R}} / 108 \underline{\mathrm{N}} / 437 \mathrm{~A} / 540 \mathrm{~K}$ & 2 & 3 & 2 & 2 & 5 & 4 \\
\hline \multicolumn{7}{|l|}{ Double } \\
\hline $5 \mathrm{II} / 59 \mathrm{C} / 108 \underline{N} / 437 \mathrm{~A} / 540 \mathrm{~K}$ & 2 & 2 & 4 & 2 & 0 & 0 \\
\hline
\end{tabular}

* S - symptomatic; $\mathrm{A}$ - asymptomatic; The mutation amino acids are underlined.

taken into account, significant associations were found between the pfcrt $76 \mathrm{~T}$ and two pfmdr1 alleles (184F and $1246 \mathrm{Y})(P<0.01)$. However, pfcrt $76 \mathrm{~T}$ was not significantly associated with $p f m d r 186 \mathrm{Y}(P=0.174)$, the mutation found associated with CQ-resistant field isolates in Asia and Africa.

\section{Mutations in antifolate drug resistance genes}

Despite relatively recent deployment of antifolate drugs for controlling malaria in western Kenya, parasites with mutations in the drug target genes, $p f d h f r$ and $p f d h p s$, were highly prevalent. The mutation at codon 108 (allele $108 \mathrm{~N}$ ) of the $p f d h f r$ gene, a major determinant of PY resistance, was ubiquitously present in all samples (Table 1). In addition, mutant alleles at codons 51 and 59 were also detected at high frequencies $(85 \%-98 \%)$. No mutation was detected at codons 16, 50, and 164 of pfdhfr. Most samples $(90 \%-100 \%)$ contained the key SD-resistance determinant mutation $\mathrm{A} 437 \mathrm{G}$ and $\mathrm{K} 540 \mathrm{E}$ in pfdhps. In contrast, the mutant $436 \mathrm{~F}$ allele was rare $(<5 \%)$, and mutant 436A allele was not detected in any locations. Further, no mutation was detected at codons 581 and 613 of pfdhps.

Increased numbers of mutations at the two antifolate target genes are associated with increased resistance to SD- 
PY. In the studied samples, single or double mutations were rarely encountered, whereas triple mutations in the $p f d h f r$ gene were the most common. When the two genes were combined, quintuple mutations $(51 \mathrm{I} / 59 \mathrm{R} / 108 \mathrm{~N}$ of pfdhfr and 437G/540E of $p f d h p s$ ) were found with a high prevalence (80-87\%) at the three sites (Fig. 1E and $1 \mathrm{~F}$ ), followed by quadruple mutations $(51 \mathrm{I} / 59 \mathrm{C} / 108 \mathrm{~N} / 437 \mathrm{G} /$ $540 \mathrm{E}, \quad 51 \mathrm{~N} / 59 \mathrm{R} / 108 \mathrm{~N} / 437 \mathrm{G} / 540 \mathrm{E}, \quad 51 \mathrm{I} / 59 \mathrm{R} / 108 \mathrm{~N} /$ $437 \mathrm{G} / 540 \mathrm{~K}, \quad 51 \mathrm{I} / 59 \mathrm{R} / 108 \mathrm{~N} / 437 \mathrm{~A} / 540 \mathrm{E})(8 \%-16 \%)$ (Table 2).

\section{Mutation frequency difference between asymptomatic and symptomatic samples}

The $p f c r t$ K76T mutation frequencies were not significantly different in the asymptomatic and symptomatic samples in the lowland Kombewa site (96\% vs. 94\%; Fisher's exact test, $P=0.537$ ) and two highland sites ( $86 \%$ vs. $92 \%$ in Kakamega, $\chi^{2}=1.41$, df $=1, P=0.235 ; 80 \%$ vs. $83 \%$ in Kisii, $\chi^{2} 0.03$, df $=1, P=0.863$ ). Similarly, there was no significantly difference in mutation frequencies of $p d m d r 1$ gene at test codons between asymptomatic and symptomatic samples in the lowland (Kombewa: $\chi^{2}=1.44, \mathrm{df}=$ $1, P=0.230$ at codon N86Y; $\chi^{2}=0.33, \mathrm{df}=1, P=0.566$ at codon Y184F; $\chi^{2}=0, \mathrm{df}=1, P=1.000$ at codon D1246Y) and two highland sites (Kakamega: $\chi^{2}=0.07$, $\mathrm{df}=1, P=$ 0.791 at codon N86Y; $\chi^{2}=0.01, \mathrm{df}=1, P=0.920$ at codon Y184F; $\chi^{2}=0.26, \mathrm{df}=1, P=0.610$ at codon D1246Y. Kisii: $\chi^{2}=0.87, \mathrm{df}=1, P=0.351$ at codon N86Y; $\chi^{2}=0, \mathrm{df}=1$, $P=1.000$ at codon Y184F; $\chi^{2}=1.40, \mathrm{df}=1, P=0.237$ at codon D1246Y). Similarly, for the $p f d h f r / p f d h p s$ quintuple mutation frequencies, no significantly difference was found in the asymptomatic and symptomatic samples in both lowland site (Kombewa: $\chi^{2}=0.16, \mathrm{df}=1, P=0.689$ ) and highland sites (Kakamega: $\chi^{2}=0.20, \mathrm{df}=1, P=0.655$. Kisii: $\chi^{2}=0.32, \mathrm{df}=1, P=0.572$ ).

\section{Discussion}

In the present study, we analyzed the mutations of four known drug resistance genes in both highland and lowland parasite populations of western Kenya. We showed that the frequencies of key mutations in the pfcrt, pfmdr1, $p f d h p s$, and $p f d h f r$ genes that were implicated in resistance to CQ and SP were very high. We further demonstrated that there was no difference in the frequencies of key mutations between symptomatic and asymptomatic malaria volunteers. Our experiment design did not allow us to test clinical or parasitological efficacy in symptomatic infections after treatment; nor was the mutation prevalence/in vivo resistance before 1998 when the national policies of treating uncomplicated malaria were changed to SP was examined. Nevertheless, the big sample size in this study coupled to lack of differences in the frequency of resistant parasite genotypes in the two highland areas and the low land area clearly demonstrates a high frequency of drug resistant mutants circulating in the study areas.
Resistance to CQ is largely determined by the K76T mutation in the pfcrt gene, and enhanced by mutations at other sites of this gene and mutations in the $p f m d r 1$ gene. Since resistant phenotypes often have fitness costs [37], their prevalence is expected to decline after removal of the selective pressure. For example, the prevalence of mutant alleles of pfcrt 76T decreased from $64.5 \%$ in 2002 to $16 \%$ in 2004 and that of mutant pfmdr1 $86 \mathrm{Y}$ alleles decreased from $46.6 \%$ to $2.7 \%$ two and half year after CQ withdrawal in coastal Tanzania [38]. Kublin et al. reported that the prevalence of the chloroquine-resistant $p f c r t 76 \mathrm{~T}$ genotype decreased from $85 \%$ in 1992 to $13 \%$ in 2000 . In 2001 , chloroquine cleared $100 \%$ of 63 asymptomatic $P$. falciparum infections, no isolates were resistant to chloroquine in vitro, and no infections with the chloroquineresistant pfcrt 76T genotype were detected [39]. Similarly, Laufer et al. demonstrated that chloroquine was again an efficacious treatment for malaria, 12 years after it was withdrawn from use in Malawi [40]. Although Kenya had a similar drug policy, the pfcrt K76T mutation in western Kenya was still predominant. Consistent with the observation of high pfcrt K76T mutation frequency in the study sites, pfmdr1 mutations that enhance CQ resistance (e.g., $86 \mathrm{Y}$ ) were also present at relatively high frequencies (37.2 - 45.2\%) in western Kenya. This may be partly caused by wide availability and consumption of CQ after it was replaced as first-line antimalarial drug by antifolate drug (SP) in $1998[12,13]$. Our results indicated that parasite populations in western Kenya were still highly resistant to 4-aminoquinoline drugs.

Several years after introduction of SP as the first-line antimalarial drug in Kenya, mutant genotypes have already become common. We found that mutations at codon 108 of the $p f d h f r$ gene and codon 437 of the $p f d h p s$ gene, which are the major determinants for sulfadoxine and pyrimethamine resistance, respectively, were highly prevalent in our study sites. Furthermore, increased resistance to antifolate drugs was correlated with mutations at additional sites, which were also detected in our present study. In Kenya, Nzila et al. [41] reported that the pfdhfr triple mutant (codons 108, 51 and 59) was associated with seven-day treatment failure using Fansidar, and this association was strengthened by the presence of double mutations of the pfdhps gene at codons 437 and 540. Such "quintuple" mutants were also strongly correlated with Fansidar treatment failure in Malawi [26]. These quintuple mutants have already reached $80-87 \%$ prevalence in the parasite populations in western Kenya. This is consistent with the observation in another highland site in Chogoria, near Mount Kenya [42]. Since mutations at different sites of the $p f d h f r$ and $p f d h p s$ genes might be a stepwise process, two mutations at codon 59 of $p f d h f r$ and codon 540 of $p f d h p s$ can accurately predict the presence of this quintuple mutant [26]. The molecular method for monitoring antifolate resistance in $P$. falciparum can thus 
be simplified to detect the presence of these two mutations. This method has been shown to provide the best means of predicting clinical treatment outcomes in the patient population, which consists primarily of children from endemic areas of Africa [36]. In our study, either of these two mutations has exceeded $75 \%$ prevalence in the parasite populations, suggesting that at least $50 \%$ of the parasites carry these double mutations. Consistent with other genotype studies of $p f d h f r$ from Kenyan isolates, we did not observe mutations at codon 164 [23,41,43], although McCollum et al. identified 164L mutation in several samples in western Kenya [21].

The causes of the malaria epidemics in the East African highlands are complex and could be the result of interactions between environmental changes, vectors and parasites. Antimalarial drug resistance has been invoked as a major factor [9], however the molecular epidemiology of drug resistance in these highlands is unknown. Mbaisi et al. [43] reported a significantly lower prevalence of mutations at codon 437 of the pfdhps gene and codons 86 and 1246 of the pfmdr gene in lowland (Kisumu) samples than in highland (Kericho, Magadi, and Entosopia) samples in western Kenya, whereas this trend was the opposite for the mutation at codon 436 of the pfdhps gene. In contrast, our study did not detect significant differences in frequency of mutations at 14 codons in four drug resistant genes between samples from lowland and highland areas in western Kenya, although the prevalence of mutations at codons 86 and 1246 of the pfmdr gene was higher in samples from the lowlands (Kombewa) than in those from the highlands (Kakamega and Kisii). This result suggests either a similar drug selection pressure or significant gene flow between lowland and highland parasite populations aided by human travel [44], as detected by microsatellite and merozoite surface protein 1 and 2 ( $m s p-1$ and $m s p-2$ ) [45].

\section{Conclusion}

Together with the evidence that there was no significance difference in the frequencies of key resistance-conferring mutations in $p f c r t$, pfmdr1, pfdhps, and pfdhfr genes between symptomatic and asymptomatic malaria infections in western Kenya highland, high frequencies of these mutations in symptomatic and asymptomatic infections suggest that drug resistance of malaria parasites may be an important contributor to malaria-induced morbidity and mortality. However, the role of drug resistance as a driving force for malaria outbreaks in the highlands has not been established. If drug resistance were the main driving force, the lowland and highland sites should expect similar epidemic pattern of malaria incidence. Moreover, drug resistance level should increase over time until a new antimalarial drug is adopted. Thus, the number of malaria patients would be expected to increase gradually over time, but malaria incidence should not exhibit a large inter-annual variation. In contrast, dramatic fluctuations in malaria incidence in the African highlands were observed $[9,46,47]$. Significant association between climate variability and malaria incidence suggests that climate factors may play an important role in the East African highlands [47]. Further studies are required to examine the interactions between climate factors and drug resistance on malaria incidence in African highlands.

\section{Competing interests}

The authors declare that they have no competing interests.

\section{Authors' contributions}

DZ: Participated in the design of the study, conducted data collection, statistical analysis and drafting of the manuscript. YA: Conducted sample collection and helped with writing the manuscript. AG: Faciliated and conducted field sample collection. LC: Participated in the design of the study, interpretation of data and revising the manuscript. DM: Participated in experimental work and revising of the manuscript. GY: Conceived the study, participated in collection of samples, and participated in manuscript preparation. All authors read and approved the final manuscript.

\section{Acknowledgements}

The authors thank Hong Chen, Emmanuel A. Temu, Thomas Loescher, David Warhurst and two anonymous reviewers for constructive comments on the manuscript. The work was supported by NIH grants ROI AI50243, D43 TW0I505, and R03 TW007360.

\section{References}

I. Snow RW, Guerra CA, Noor AM, Myint HY, Hay SI: The global distribution of clinical episodes of Plasmodium falciparum malaria. Nature 2005, 434:214-2I7.

2. Sachs J, Malaney P: The economic and social burden of malaria. Nature 2002, 4 I 5:680-685.

3. Garnham PCC: Malaria epidemics at exceptionally high altitudes in Kenya. British Med J 1945, 2:45-47.

4. Roberts JMD: The control of epidemic malaria in the high lands of western Kenya. Part I. Before the campaign. Am J Trop Med Hyg 1964, 6 I: I61-168.

5. Lepers JP, Deloron P, Fontenille D, Coulanges P: Reappearance of falciparum malaria in central highland plateaux of Madagascar. Lancet 1988, 1:586.

6. Some ES: Effects and control of highland malaria epidemic in Uasin Gishu District, Kenya. East Afr Med J 1994, 71:2-8.

7. Lindsay SW, Martens WJ: Malaria in the African highlands: past, present and future. Bull World Health Organ 1998, 76:33-45.

8. Malakooti MA, Biomndo K, Shanks GD: Reemergence of epidemic malaria in the highlands of western Kenya. Emerg Infect Dis 1998, 4:67|-676.

9. Hay SI, Cox J, Rogers DJ, Randolph SE, Stern DI, Shanks GD, Myers $\mathrm{MF}$, Snow RW: Climate change and the resurgence of malaria in the East African highlands. Nature 2002, 41 5:905-909.

10. Fogh S, Jepsen S, Efferson P: Chloroquine-resistant Plasmodium falciparum in Kenya. Trans R Soc Trop Med Hyg 1979, 73:228-229.

II. Anabwani GM, Esamai FO, Menya DA: A randomised controlled trial to assess the relative efficacy of chloroquine, amodiaquine, halofantrine and fansidar in the treatment of uncomplicated malaria in children. East Afr Med J 1996, 73(3): I55-I58.

12. Shretta R, Omumbo J, Rapuoda B, Snow RW: Using evidence to change antimalarial drug policy in Kenya. Trop Med Int Health 2000, 5:755-764. 
13. Amin AA, Walley T, Kokwaro GO, Winstanley PA, Snow RW: Commentary: Reconciling national treatment policies and drug regulation in Kenya. Health Policy Plann 2007, 22: I I I- I I 2 .

14. Wellems T, Plowe C: Chloroquine-resistant malaria. J Infect Dis 200I, 184:770-776.

15. White NJ: Antimalarial drug resistance. J Clin Invest 2004, I I 3: 1084-1092.

16. Wongsrichanalai C, Pickard AL, Wernsdorfer WH, Meshnick SR: Epidemiology of drug-resistant malaria. Lancet Infect Dis 2002, 2:209-218.

17. Hayton K, Su XZ: Genetic and biochemical aspects of drug resistance in malaria parasites. Curr Drug Targets Infect Disord 2004, 4: I- 10.

18. Sisowath C, Stromberg J, Martensson A, Msellem M, Obondo C, Björkman A, Gil JP: In vivo selection of Plasmodium falciparum pfmdrl $86 \mathrm{~N}$ coding alleles by artemether-lumefantrine (Coartem). J Infect Dis 2005, 191:1014-1017.

19. Ouellette M: Biochemical and molecular mechanisms of drug resistance in parasites. Trop Med Int Health 200I, 6:874-876.

20. Peterson DS, Milhous WK, Wellems TE: Molecular basis of differential resistance to cycloguanil and pyrimethamine in Plasmodium falciparum malaria. Proc Natl Acad Sci USA 1990, 87:30I8-3022.

21. McCollum AM, Poe AC, Hamel M, Huber C, Zhou Z, Shi YP, Ouma $P$, Vulule J, Bloland P, Slutsker L, Barnwell JW, Udhayakumar V, Escalante AA: Antifolate resistance in Plasmodium falciparum: multiple origins and identification of novel dhfr alleles. J Infect Dis 2006, 194:189-197.

22. Triglia T, Cowman AF: The mechanism of resistance to sulfa drugs in Plasmodium falciparum. Drug Resist Update 1999, 2:15-19.

23. Wang P, Lee CS, Bayoumi R, Djimde A, Doumbo O, Swedberg G, Dao LD, Mshinda H, Tanner M, Watkins WM, Sims PF, Hyde JE: Resistance to antifolate in Plasmodium falciparum monitored by sequence analysis of dihydropteroate synthetase and dihydrofolate reductase alleles in a larger number of field samples of diverse origin. Mol Biochem Parasitol 1997, 89: I6I-I77.

24. Curtis J, Duraisingh MT, Trigg JK, Mbwana H, Warhurst DC, Curtis CF: Direct evidence that asparagine at position 108 of the Plasmodium falciparum dihydrofolate reductase is involved in resistance to antifolate drugs in Tanzania. Trans $R$ Soc Trop Med Hyg 1996, 90:678-680

25. Djimde A, Doumbo O, Cortese J, Kayentao K, Doumbo S, Diourté Y, Dicko A, Su XZ, Nomura T, Fidock DA, Wellems TE, Plowe CV Coulibaly D: A molecular marker for chloroquine-resistant falciparum malaria. New Engl J Med 200I, 344:257-263.

26. Kublin JG, Dzinjalamala FK, Kamwendo DD, Malkin EM, Cortese JF, Martino LM, Mukadam RA, Rogerson SJ, Lescano AG, Molyneux ME, Winstanley PA, Chimpeni P, Taylor TE, Plowe CV: Molecular markers for failure of sulfadoxine-pyrimethamine and chlorproguanil-dapsone treatment of Plasmodium falciparum malaria. J Infect Dis 2002, 185:380-388.

27. Ndenga B, Githeko AK, Mushinzimana E, Munyekenye G, Atieli $H$ Wamai P, Mbogo C, Minakawa N, Zhou G, Yan G: Population dynamics of malaria vectors in highlands and lowlands of western Kenya. J Med Entomol 2006, 43:200-206.

28. Wooden J, Kyes S, Sibley CH: PCR and Strain Identification in Plasmodium falciparum. Parasitol Today 1993, 9:303-305.

29. Singh B, Bobogare A, Cox-Singh J, Snounou G, Abdullah MS, Rahman $H A$ : A genus and species-specific nested polymerase chain reaction malaria detection assay for epidemiologic studies. Am J Trop Med Hyg 1999, 60:687-692.

30. Schneider AG, Premji Z, Felger I, Smith T, Abdulla S, Beck HP, Mshinda $\mathrm{H}$ : A point mutation in codon 76 of pfort of $P$. falciparum is positively selected for by Chloroquine treatment in Tanzania. Infect Genet Evol 2002, I:183-189.

31. Flueck TP, Jelinek T, Kilian AH, Adagu IS, Kabagambe G, Sonnenburg $\mathrm{F}$, Warhurst DC: Correlation of in vivo-resistance to chloroquine and allelic polymorphisms in Plasmodium falciparum isolates from Uganda. Trop Med Int Health 2000, 5: I 74- I 78.

32. Duraisingh MT, Jones P, Sambou I, von Seidlein L, Pinder M, Warhurst DC: The tyrosine-86 allele of the pfmdrl gene of Plasmodium falciparum is associated with increased sensitivity to the antimalarials mefloquine and artemisinin. Mol Biochem Parasitol 2000, 108:13-23.
33. Sisowath C, Ferreira PE, Bustamante LY, Dahlström S, Mårtensson A, Björkman A, Krishna S, Gil JP: The role of pfmdrl in Plasmodium falciparum tolerance to artemether-lumefantrine in Africa. Trop Med Int Health 2007, 1 2:736-742.

34. Plowe CV, Djimde A, Bouare M, Doumbo O, Wellems TE: Pyrimethamine and proguanil resistance-conferring mutations in Plasmodium falciparum dihydrofolate reductase: polymerase chain reaction methods for surveillance in Africa. Am J Trop Med Hyg 1995, 52:565-568.

35. Duraisingh MT, Curtis J, Warhurst DC: Plasmodium falciparum: detection of polymorphisms in the dihydrofolate reductase and dihydropteroate synthetase genes by PCR and restriction digestion. Exp Parasitol 1998, 89: I-8.

36. Kyabayinze D, Cattamanchi A, Kamya MR, Rosenthal PJ, Dorsey G: Validation of a simplified method for using molecular markers to predict sulfadoxine-pyrimethamine treatment failure in African children with falciparum malaria. Am J Trop Med Hyg 2003, 69:247-252.

37. Yang Z, Zhang Z, Sun X, Wan W, Cui L, Zhang X, Zhong D, Yan G, Cui $L:$ Molecular analysis of chloroquine resistance in Plasmodium falciparum in Yunnan Province, China. Trop Med Intl Health 2007, 12:1051-1060.

38. Temu EA, Kimani I, Tuno N, Kawada H, Minjas JN, Takagi M: Monitoring chloroquine resistance using Plasmodium falciparum parasites isolated from wild mosquitoes in Tanzania. $\mathrm{Am}$ Trop Med Hyg 2006, 75: I I 82-I I 87.

39. Kublin JG, Cortese JF, Njunju EM, Mukadam RA, Wirima JJ, Kazembe PN, Djimdé AA, Kouriba B, Taylor TE, Plowe CV: Reemergence of chloroquine-sensitive Plasmodium falciparum malaria after cessation of chloroquine use in Malawi. J Infect Dis 2003, I87: $1870-1875$

40. Laufer MK, Thesing PC, Eddington ND, Masonga R, Dzinjalamala FK, Takala SL, Taylor TE, Plowe CV: Return of chloroquine antimalarial efficacy in Malawi. N Engl J Med 2006, 355:1959-1966.

4I. Nzila AM, Mberu EK, Sulo J, Dayo H, Winstanley PA, Sibley CH, Watkins WM: Towards an understanding of the mechanism of pyrimethamine-sulfadoxine resistance in Plasmodium falciparum: genotyping of dihydrofolate reductase and dihydropteroate synthase of Kenyan parasites. Antimicrob Agents Chemother 2000, 44:991-996.

42. Omar SA, Adagu IS, Gump DW, Ndaru NP, Warhurst DC: Plasmodium falciparum in Kenya: high prevalence of drug-resistanceassociated polymorphisms in hospital admissions with severe malaria in an epidemic area. Ann Trop Med Parasitol 200I, 95:66I-669.

43. Mbaisi A, Liyala P, Eyase F, Achilla R, Akala H, Wangui J, Mwangi J, Osuna F, Alam U, Smoak BL, Davis JM, Kyle DE, Coldren RL, Mason $C$, Waters NC: Drug susceptibility and genetic evaluation of Plasmodium falciparum isolates obtained in four distinct geographical regions of Kenya. Antimicrob Agents Ch 2004, 48:3598-360I.

44. Shanks GD, Hay SI, Omumbo JA, Snow RW: Malaria in Kenya's western highlands. Emerg Infect Dis 2005, I I: | 425- I 432.

45. Zhong D, Afrane Y, Githeko A, Yang Z, Cui L, Menge DM, Temu EA, Yan G: Plasmodium falciparum Genetic Diversity in Western Kenya Highlands. Am J Trop Med Hyg 2007, 77: $1043-1050$.

46. Snow RW, Craig M, Deichmann U, Marsh K: Estimating mortality, morbidity and disability due to malaria among Africa's nonpregnant population. Bull World Health Organ 1999, 77:624-640.

47. Zhou G, Minakawa N, Githeko AK, Yan G: Association between climate variability and malaria epidemics in the East African highlands. Proc Natl Acad Sci USA 2004, I 0 I:2375-80.

\section{Pre-publication history}

The pre-publication history for this paper can be accessed here:

\section{http://www.biomedcentral.com/1471-2334/8/105/pre} pub 